\title{
Formation of quasicrystals in Zr46.8Ti8.2Cu7.5Ni10Be27.5 bulk glass
}

\author{
Wanderka, N.; Macht, M. P.; Siedel, M.; Mechler, S.; Ståhl, Kenny; Jiang, Jianzhong
}

Published in:

Applied Physics Letters

Link to article, DOI:

$10.1063 / 1.1329636$

Publication date:

2000

Document Version

Publisher's PDF, also known as Version of record

Link back to DTU Orbit

Citation (APA):

Wanderka, N., Macht, M. P., Siedel, M., Mechler, S., Ståhl, K., \& Jiang, J. (2000). Formation of quasicrystals in Zr46.8Ti8.2Cu7.5Ni10Be27.5 bulk glass. Applied Physics Letters, 77(24), 3935-3937. https://doi.org/10.1063/1.1329636

\section{General rights}

Copyright and moral rights for the publications made accessible in the public portal are retained by the authors and/or other copyright owners and it is a condition of accessing publications that users recognise and abide by the legal requirements associated with these rights.

- Users may download and print one copy of any publication from the public portal for the purpose of private study or research.

- You may not further distribute the material or use it for any profit-making activity or commercial gain

- You may freely distribute the URL identifying the publication in the public portal 


\title{
Formation of quasicrystals in $\mathrm{Zr}_{46.8} \mathrm{Ti}_{8.2} \mathrm{Cu}_{7.5} \mathrm{Ni}_{10} \mathrm{Be}_{27.5}$ bulk glass
}

\author{
N. Wanderka, M.-P. Macht, M. Seidel, and S. Mechler \\ Hahn-Meitner-Institut Berlin, Glienicker Str. 100, D-14109 Berlin, Germany \\ K. Ståhl \\ Department of Chemistry, Building 207, Technical University of Denmark, DK-2800 Lyngby, Denmark \\ J. Z. Jiang ${ }^{\text {a) }}$ \\ Department of Physics, Building 307, Technical University of Denmark, DK-2800 Lyngby, Denmark
}

(Received 1 June 2000; accepted for publication 9 October 2000)

\begin{abstract}
The formation of the quasicrystalline phase is observed as a first step of crystallization during isothermal annealing of the $\mathrm{Zr}_{46.7} \mathrm{Ti}_{8.3} \mathrm{Cu}_{7.5} \mathrm{Ni}_{10} \mathrm{Be}_{27.5}$ bulk glass. The structure of the quasicrystals and the sequence of phase formation have been investigated by $\mathrm{x}$-ray powder diffraction and transmission electron microscopy. The structure of the quasicrystals is determined to be primitive icosahedral with a quasilattice constant of $4.779 \AA$. The quasicrystals decompose into several intermetallic compounds after prolonged annealing at lower temperatures or in a short time period (less than $5 \mathrm{~min}$ ) at high temperatures above $683 \mathrm{~K}$. (C) 2000 American Institute of Physics.

[S0003-6951(00)00949-9]
\end{abstract}

Since the discovery of the icosahedral phase ( $i$ phase) in rapidly quenched binary or ternary Al-based alloy systems, there have been extensive studies on quasicrystals. ${ }^{1-4}$ Some studies showed that crystallization of amorphous alloys may evolve quasicrystalline phases, as in the case of $\mathrm{Pb}_{60} \mathrm{U}_{20} \mathrm{Si}_{20}{ }^{3}$ and $\mathrm{Ti}_{53} \mathrm{Zr}_{27} \mathrm{Ni}_{30}{ }^{5}$ Recently, quasicrystals were observed by crystallization of multicomponent alloy systems, such as $\mathrm{ZrCuAl}, \mathrm{ZrCuNiAl}, \mathrm{ZrCuAlPd}$, ZrTiCuNiAl, and ZrAlNiCuAg amorphous alloys. ${ }^{6-10}$ Such systems have a high glass forming ability and are stable against crystallization for long times in the temperature range of the supercooled liquid above the glass transition. They can be produced in the form of metallic bulk glasses. ${ }^{11}$ However, most of the reported work about quasicrystal formation is focused on thin ribbons $(10-40 \mu \mathrm{m})$. The effect of cooling rate on the formation of quasicrystals in the ZrAlCuNiTi system was investigated by Xing et al. ${ }^{9}$ and found that the cooling rate does affect the formation of quasicrystals. The $\mathrm{ZrTiCuNiBe}$ bulk glasses have potential technical applications due to their favorable physical and mechanical properties and excellent processing capabilities. ${ }^{12}$ Several investigations of the crystallization behavior of these glasses have been undertaken during the last few years. ${ }^{12,13}$ In this letter, we report the formation of quasicrystals as a first stage in the crystallization process of the $\mathrm{Zr}_{46.7} \mathrm{Ti}_{8.3} \mathrm{Cu}_{7.5} \mathrm{Ni}_{10} \mathrm{Be}_{27.5}$ (V4) bulk glass, studied by $\mathrm{x}$-ray powder diffraction (XRD) and transmission electron microscopy (TEM).

Ingots of the V4 bulk glass were produced by alloying the pure components by induction melting in a levitation device under purified Ar atmosphere and quenching by contact with a water cooled copper surface. This material was remelted in a fused silica crucible and die-cast into a copper mold, to obtain $60 \mathrm{~mm}$ long rods with diameters of $5 \mathrm{~mm}$. The average cooling rate was estimated to be $>20 \mathrm{~K} / \mathrm{s}$. Samples from both ends of the rods were mechanically polished and analyzed by optical microscopy and scanning elec-

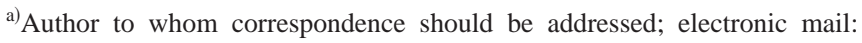
jiang@fysik.dtu.dk
}

tron microscopy to ascertain the absence of undesirable primary crystals ${ }^{14}$ which cannot be detected by XRD below a volume fraction of about $3 \%$. The thermal behavior of the glass between 473 and $873 \mathrm{~K}$ was studied by a Perkin Elmers-Pyris1 differential scanning calorimetry (DSC) at a heating rate of $4 \mathrm{~K} / \mathrm{min}$ under a flow of purified argon.

The long time heat treatments were performed at 643 and $653 \mathrm{~K}$ for times between 2 and $156 \mathrm{~h}$ in a tube furnace under vacuum of $10^{-4} \mathrm{~Pa}$. The annealing temperatures were controlled to be better than $\pm 1.5 \mathrm{~K}$. The XRD spectra were measured with $\mathrm{Cu} K_{\alpha}$ radiation in the $\theta-2 \theta$ configuration by use of a Bruker AXS D8 diffractometer equipped with a graphite monochromator and a scintillation counter for $\lambda$ $=0.5-3 \AA$. High-temperature $x$-ray powder diffraction measurements were performed using synchrotron radiation at beamline I711 at the MAX II synchrotron in Lund, Sweden, utilizing a Huber G670 imaging plate Guinier camera. The wavelength, $1.52225(1) \AA$, was determined using a Si standard. In order to exclude oxygen from the sample, the alloy was mounted on the top of a quartz capillary, which was pumped down to $10^{-4} \mathrm{~Pa}$ and then sealed. The diffraction patterns were collected in the range $30^{\circ}-80^{\circ}$ in 2theta steps of $0.005^{\circ}$, and accumulated for $5 \mathrm{~min}$. The temperature stability of the sample was $\pm 1 \mathrm{~K}$. TEM specimens were prepared from thin slice cut from the rod and thinned electrochemically by jet polishing at $263 \mathrm{~K}$ with $30 \mathrm{~V}$, using a solution of $\mathrm{CH}_{3} \mathrm{COOH}$ and $\mathrm{HClO}_{4}$ in the ratio of 9:1. Subsequently, the specimens were ion beam thinned in a Gatan 600 ion mill. The microstructure of selected samples and high-resolution TEM linked with nanobeam electron diffraction was characterized by a Philips CM 30 microscope operated at $300 \mathrm{kV}$.

By the DSC scan in Fig. 1 the thermal behavior of the V4 bulk glass is indicated. This glass shows a wide supercooled liquid region of $\Delta T=T_{x}-T_{g}=122 \mathrm{~K}$ between the glass transition at $T_{g}=603 \mathrm{~K}$, and the onset of crystallization at $T_{x}=725 \mathrm{~K}$. The crystallization behavior is characterized by only one main heat release peak in a narrow temperature range. Figure 2 shows the $\mathrm{x}$-ray powder diffraction pattern of 


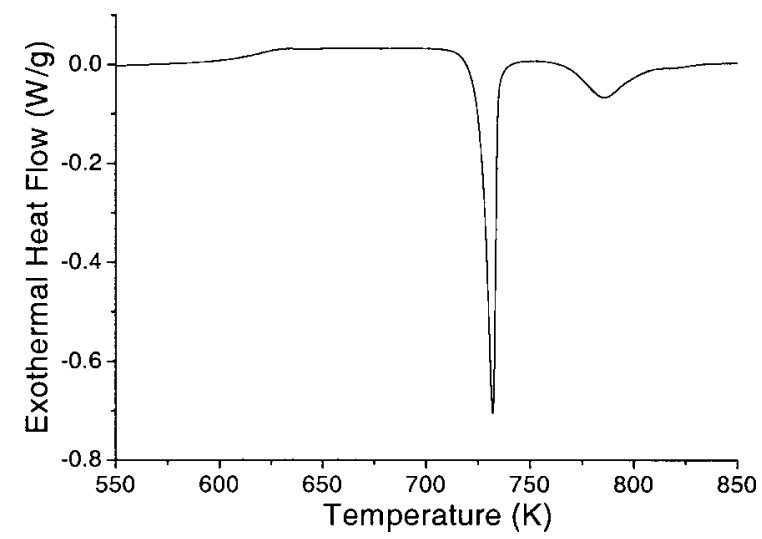

FIG. 1. The DSC curve of the $\mathrm{Zr}_{46.8} \mathrm{Ti}_{8.2} \mathrm{Cu}_{7.5} \mathrm{Ni}_{10} \mathrm{Be}_{27.5}$ bulk glass at a heating rate of $4 \mathrm{~K} / \mathrm{min}$ under a flow of purified argon.

the V4 bulk glass annealed at $643 \mathrm{~K}$ for $12 \mathrm{~h}$ in vacuum. A primitive icosahedral structure was found to be the most promising indexing scheme. The icosahedral Miller indices are generated by cyclic permutations of $\left(q_{x}, q_{y}, q_{z}\right)=( \pm 1$, $\pm \delta, 0)$. Six independent vectors are expressed by: $q_{1}$ $=(1, \delta, 0) ; \quad q_{2}=(1,-\delta, 0) ; \quad q_{3}=(0,1, \delta) ; q_{4}=(0,1,-\delta) ; q_{5}$ $=(\delta, 0,1)$; and $q_{6}=(-\delta, 0,1)$, where $\delta$ is the golden mean, 1.618. As an example, the (110000) peak is found at $q$ $=Q_{0}\left(q_{1}+q_{2}\right)=(2,0,0)$ and $Q_{0}=2 \pi / a$, where $a$ is the quasilattice constant. The quasilattice constant is found to be $a=4.779$ (1) $\AA$. The peak (2theta $\approx 36^{\circ}, q \approx 2.5 \AA^{-1}$ ) is a choice for the basic $(100000)$ reciprocal lattice vector. The nanobeam electron diffraction patterns obtained from the sample annealed at $643 \mathrm{~K}$ for $17 \mathrm{~h}$ can also be indexed according to the icosahedral Miller indices mentioned earlier. It is found that quasicrystalline particles formed in the annealed sample have a size distribution from about 20-60 nm and a nonspherical morphology. They are homogeneously dispersed in the amorphous matrix. Figure 3 exemplifies a TEM image with a five-fold zone axis of an icosahedral phase embedded in an amorphous matrix and the corresponding nanobeam electron diffraction patterns for the V4 bulk glass annealed at $643 \mathrm{~K}$ for $17 \mathrm{~h}$.

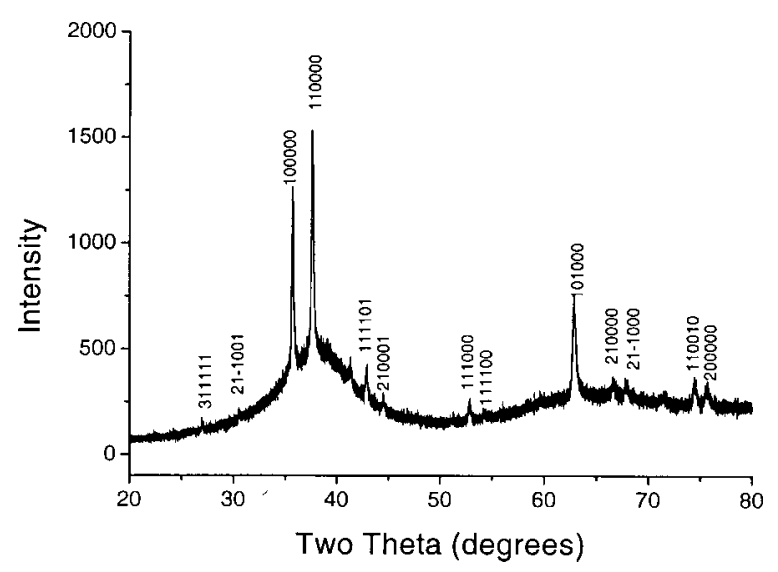

FIG. 2. The x-ray powder diffraction pattern of the $\mathrm{Zr}_{46.8} \mathrm{Ti}_{8.2} \mathrm{Cu}_{7.5} \mathrm{Ni}_{10} \mathrm{Be}_{27.5}$ bulk glass annealed at $643 \mathrm{~K}$ for $12 \mathrm{~h}$ in vacuum, recorded using $\mathrm{Cu} K_{\alpha}$ radiation. Labels are the icosahedral Miller indices which are generated by cyclic permutations of $\left(q_{x}, q_{y}, q_{z}\right)=( \pm 1, \pm \delta, 0)$ with six independent vectors expressed by: $q_{1}=(1, \delta, 0) ; \quad q_{2}=(1,-\delta, 0) ; \quad q_{3}=(0,1, \delta) ; \quad q_{4}=(0,1$, $-\delta) ; q_{5}=(\delta, 0,1)$; and $q_{6}=(-\delta, 0,1)$, where $\delta$ is the golden mean of 1.618 . $\mathrm{Zr}_{46.8} \mathrm{Ti}_{8.2} \mathrm{Cu}_{7.5} \mathrm{Ni}_{10} \mathrm{Be}_{27.5}$ bulk glass annealed at $643 \mathrm{~K}$ for various times in vacuum, recorded using $\mathrm{Cu} K_{\alpha}$ radiation. icosahedral phase embedded in amorphous matrix and the corresponding nanobeam electron diffraction pattern for the $\mathrm{Zr}_{46.8} \mathrm{Ti}_{8.2} \mathrm{Cu}_{7.5} \mathrm{Ni}_{10} \mathrm{Be}_{27.5}$ bulk glass annealed at $643 \mathrm{~K}$ for $17 \mathrm{~h}$ in vacuum.

Figure 4 depicts the crystallization behavior of the V4 bulk glass at $643 \mathrm{~K}$ for various annealing times. After $5 \mathrm{~h}$ annealing no indication of crystallization is visible, i.e., the diffraction pattern is identical to the as-casted sample. After $6 \mathrm{~h}$, tiny quasicrystals are observed while they increase in intensity with the annealing time. Two new peaks at $2 \theta$ $\approx 39^{\circ}(d \approx 2.3 \AA)$ and $41.5^{\circ}$ together with quasicrystals and residual amorphous phase are observed in the pattern recorded for the sample annealed for $12 \mathrm{~h}$. After $18 \mathrm{~h}$, $\mathrm{Be}_{2} \mathrm{Zr}, \mathrm{Zr}_{2} \mathrm{Cu}$ and some as yet unidentified phases (most likely, $\mathrm{Ti}_{2} \mathrm{Ni}$-like and $\mathrm{NiZr}_{2}$-like phases) appear. Simultaneously a strong decrease of the volume fraction of the glass with annealing time is observed by DSC measurements. With further annealing, the amount of the quasicrystalline phase decreases while the peak intensities of the intermetallic compounds increase. This result indicates the quasicrystals formed in the early stage of crystallization are metastable phase, which decompose into intermetallic compounds. The crystallization processes of the V4 bulk glass at low temperatures as a function of annealing time is suggested to be: amorphous $\rightarrow$ amorphous + quasicrystal $\rightarrow$ amorphous + quasicrystal $+\mathrm{Be}_{2} \mathrm{Zr}+\mathrm{Zr}_{2} \mathrm{Cu}+$ unidentified phases $\rightarrow \mathrm{Be}_{2} \mathrm{Zr}+\mathrm{Zr}_{2} \mathrm{Cu}$ + unidentified phases.

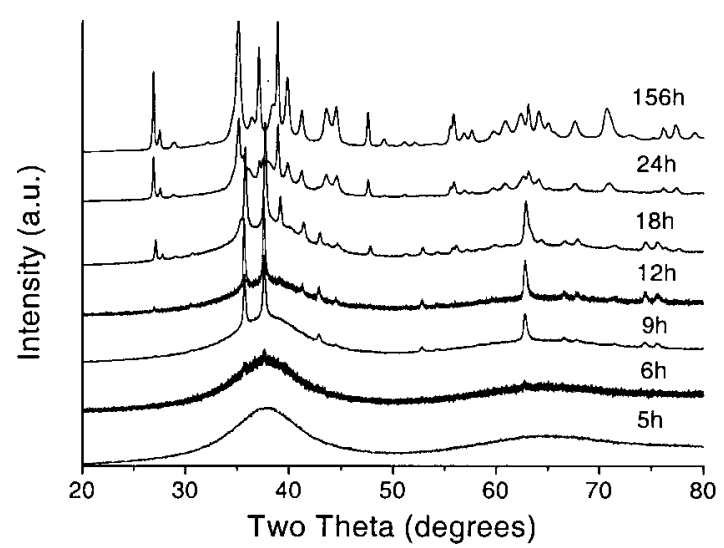

FIG. 4. X-ray powder diffraction patterns of crystallization processes in the AIP license or copyright; see http://apl.aip.org/apl/copyright.jsp 


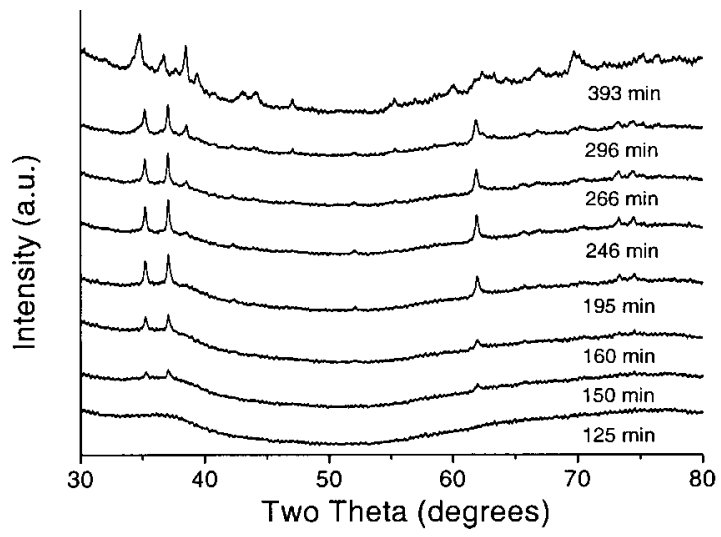

FIG. 5. High-temperature $\mathrm{x}$-ray powder diffraction patterns of the quasicrystalline phase in the $\mathrm{Zr}_{46.8} \mathrm{Ti}_{8.2} \mathrm{Cu}_{7.5} \mathrm{Ni}_{10} \mathrm{Be}_{27.5}$ bulk glass at $663 \mathrm{~K}$ in vacuum for various times, recorded using synchrotron radiation and a wavelength of $1.52225 \AA$.

The correlation of the formation of quasicrystals with annealing temperature (from 653 to $728 \mathrm{~K}$ ) and time was further investigated by high-temperature $\mathrm{x}$-ray powder diffraction measurements using synchrotron radiation. Figure 5 exemplifies x-ray powder diffraction patterns recorded at 663 $\mathrm{K}$ with various annealing times. The Bragg peak positions of the intermetallic compounds are almost identical in the crystallized samples annealed at high temperatures for short times and at low temperatures for long times. The crystallization behavior is similar in both cases (Figs. 4 and 5). However, the kinetics at $663 \mathrm{~K}$ is faster than that at $643 \mathrm{~K}$. Up to 125 min no crystallization can be observed by XRD. It should be noted that any phase transition which happens after this incubation period will be overseen by DSC measurements with heating rates faster than about $0.2 \mathrm{~K} / \mathrm{min}$. The first quasicrystalline phase appears in the pattern recorded after $150 \mathrm{~min}$. Upon increasing the annealing time, the intensities of the quasicrystalline peaks were enhanced at the expense of the amorphous component while the peak positions are almost identical within experimental uncertainty. After 246 min a new Bragg peak at $2 \theta \approx 38^{\circ}(d \approx 2.3 \AA)$ appears. After $393 \mathrm{~min}$ the quasicrystalline phase disappeared while several new Bragg peaks are observed, indicating the formation of $\mathrm{Be}_{2} \mathrm{Zr}, \mathrm{Zr}_{2} \mathrm{Cu}$ intermetallic compounds and some as yet unidentified phases. Furthermore, it was found that when the sample is annealed at a temperature above $683 \mathrm{~K}$ for $5 \mathrm{~min}$ the first observed crystalline phases are intermetallic compounds instead of quasicrystals. Preliminary hightemperature XRD measurements performed at ESRF, Grenoble on the V4 bulk glass do reveal the existence of the quasicrystal as well as the intermetallic compounds in the pattern recorded at $683 \mathrm{~K}$ for $1 \mathrm{~min}$. Thus, the absence of quasicrystalline phase at high temperatures may be due to the decomposition of quasicrystalline phase into intermetallic compounds in a short time period less than $5 \mathrm{~min}$. It has been reported that the formation of quasicrystals by crystallization of metallic glasses strongly depends on the composition. For example, in the $\mathrm{Pd}_{100-x-y} \mathrm{U}_{x} \mathrm{Si}_{y},(x \approx y \approx 20$ at. \%) system, the quasicrystalline phase can be formed only within a very narrow compositional range $\left(\Delta x\right.$ and $\Delta y<2$ at. \%). ${ }^{3}$ In fact, the atomic diffusion in the bulk metallic glass is fast at the high temperatures, ${ }^{15}$ which could make the formation of qua-

sicrystals more difficult at high temperatures.
Downloaded 12 Feb 2010 to 192.38.67.112. Redistribution subject to AIP license or copyright; see http://apl.aip.org/apl/copyright.jsp
It has been shown that oxygen promotes the formation of quasicrystals. ${ }^{16}$ The ZrTiCuNiBe glasses are assumed to solve oxygen easily, which can degrade the glass forming ability and the stability of the glass. ${ }^{12} \mathrm{ZrTiCuNiBe}$ glass of our production was found to contain between 0.1 and 0.3 at. \% of oxygen. At the present state it cannot be excluded that this oxygen promotes the formation of quasicrystals also in the V4 glass.

In conclusion, as a first step of crystallization during isothermal annealing of the $\mathrm{Zr}_{46.7} \mathrm{Ti}_{8.3} \mathrm{Cu}_{7.5} \mathrm{Ni}_{10} \mathrm{Be}_{27.5}$ bulk glass the formation of a quasicrystalline phase is observed. This process has been investigated by XRD and TEM. The structure of the quasicrystals was determined to be primitive icosahedral with a quasilattice constant of $4.779 \AA$ A. The quasicrystals are only formed at annealing temperatures between 643 and $663 \mathrm{~K}$ after a rather long incubation period. They decompose into several intermetallic compounds after prolonged annealing at lower temperatures or in a short time period less than $5 \mathrm{~min}$ at high temperatures above $683 \mathrm{~K}$. The crystallization sequence of the V4 bulk glass at the lower temperatures is amorphous $\rightarrow$ amorphous + quasicrystal $\rightarrow$ amorphous + quasicrystal $+\mathrm{Be}_{2} \mathrm{Zr}+\mathrm{Zr}_{2} \mathrm{Cu}$ + unidentified phases $\rightarrow \mathrm{Be}_{2} \mathrm{Zr}+\mathrm{Zr}_{2} \mathrm{Cu}+$ unidentified phases.

The authors thank T. J. Zhou for discussions and MAXLAB, Lund, HASYLAB, Hamburg, and ESRF, Grenoble for the use of the synchrotron radiation facilities. Financial support from the Danish Technical Research Council and the Danish Natural Sciences Research Council is gratefully acknowledged.

${ }^{1}$ D. Shechtman, I. Blech, D. Gratias, and J. W. Cahn, Phys. Rev. Lett. 53, 1951 (1984).

${ }^{2}$ P. A. Bancel, P. A. Heiney, P. W. Stephens, A. I. Goldman, and P. M. Horn, Phys. Rev. Lett. 54, 2422 (1985).

${ }^{3}$ S. J. Poon, A. J. Drehman, and K. R. Lawless, Phys. Rev. Lett. 55, 2324 (1985).

${ }^{4}$ D. Holland-Moritz, D. M. Herlach, and K. Urban, Phys. Rev. Lett. 71, 1196 (1993)

${ }^{5}$ V. V. Molokanov and V. N. Chebotnitov, J. Non-Cryst. Solids 117-118, 789 (1990).

${ }^{6}$ U. Koster, J. Meinhardt, S. Roos, and H. Liebertz, Appl. Phys. Lett. 69, 179 (1996).

${ }^{7}$ J. Eckert, N. Mattern, M. Zinkevitch, and M. Seidel, Mater. Trans., JIM 39, 623 (1988).

${ }^{8}$ U. Koster, J. Meinhardt, S. Roos, and R. Busch, Mater. Sci. Eng., A 226-228, 995 (1997).

${ }^{9}$ L. Q. Xing, J. Eckert, W. Loser, and L. Schultz, Appl. Phys. Lett. 73, 2110 (1998).

${ }^{10}$ M. W. Chen, T. Zhang, A. Inoue, and T. Sakural, Appl. Phys. Lett. 75, 1697 (1999).

${ }^{11}$ T. Zhang, A. Inoue, and T. Masumoto, Mater. Trans., JIM 32, 1005 (1991).

${ }^{12}$ W. L. Johnson, Mater. Sci. Forum 225-227, 35 (1996); MRS Bull. 24, 42 (1999), and references therein.

${ }^{13}$ See, for example, J. Schroers, A. Masuhr, W. L. Johnson, and R. Busch, Phys. Rev. B 60, 11855 (1999); Appl. Phys. Lett. 74, 2806 (1999); A. Masuhr, T. A. Waniuk, R. Busch, and W. L. Johnson, Phys. Rev. Lett. 82, 2290 (1999).

${ }^{14}$ N. Wanderka, Q. Wei, I. Sieber, U. Czubayko, and M.-P. Macht, Mater. Sci. Forum 312-314, 369 (1999).

${ }^{15}$ H. Ehmler, A. Heesemann, K. Ratzke, and F. Faupel, Phys. Rev. Lett. 80, 4919 (1998); X. P. Tang, U. Geyer, R. Busch, W. L. Johnson, and Y. Wu, Nature (London) 402, 160 (1999); K. Knorr, M. P. Macht, K. Freitag, and H. Mehrer, J. Non-Cryst. Solids 250-252, 669 (1999); and P. Fielitz, M.-P. Macht, V. Naundorf, and G. Frohberg, ibid. 250-252, 674 (1999).

${ }^{16}$ B. S. Murty, D. H. Ping, K. Hono, and A. Inoue, Appl. Phys. Lett. 76, 55 (2000) 